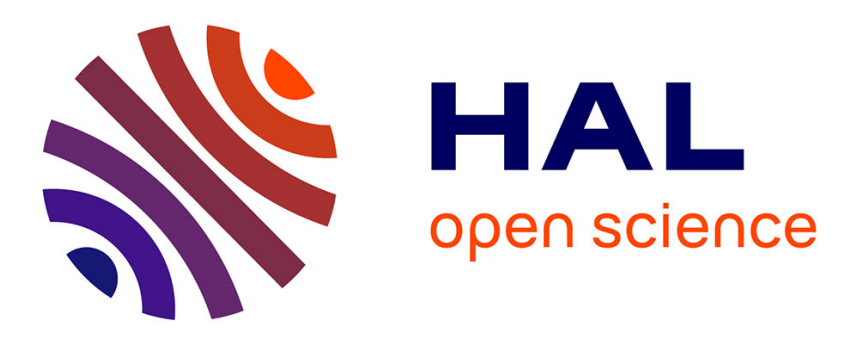

\title{
Understanding PLM and PLM Customizing: A Theoretical Fundament for a Conceptual Approach
}

Ezgi Venghaus (sucuoglu), Rainer Stark

\section{To cite this version:}

Ezgi Venghaus (sucuoglu), Rainer Stark. Understanding PLM and PLM Customizing: A Theoretical Fundament for a Conceptual Approach. 15th IFIP International Conference on Product Lifecycle Management (PLM), Jul 2018, Turin, Italy. pp.670-680, 10.1007/978-3-030-01614-2_61 . hal-02075611

\section{HAL Id: hal-02075611 \\ https://hal.inria.fr/hal-02075611}

Submitted on 21 Mar 2019

HAL is a multi-disciplinary open access archive for the deposit and dissemination of scientific research documents, whether they are published or not. The documents may come from teaching and research institutions in France or abroad, or from public or private research centers.
L'archive ouverte pluridisciplinaire HAL, est destinée au dépôt et à la diffusion de documents scientifiques de niveau recherche, publiés ou non, émanant des établissements d'enseignement et de recherche français ou étrangers, des laboratoires publics ou privés.

\section{(c)(1)}

Distributed under a Creative Commons Attribution| 4.0 International License 


\title{
Understanding PLM and PLM Customizing: A theoretical fundament for a conceptual approach
}

\author{
Ezgi Venghaus $^{1}$ (Sucuoglu) ${ }^{3}$, Rainer Stark ${ }^{2,3}$ \\ ${ }^{1}$ Volkswagen AG, Wolfsburg, Germany \\ ezgi.venghaus@volkswagen.de \\ ${ }^{2}$ Fraunhofer Institute for Production Systems and Design Technology, Berlin, Germany \\ rainer.stark@ipk.fraunhofer.de \\ ${ }^{3}$ Technische Universität Berlin, Germany \\ ezgi.sucuoglu@campus.tu-berlin.de \\ rainer.stark@tu-berlin.de
}

\begin{abstract}
The continuous development of product lifecycle management (PLM) technology depicts many needs for clarification and action especially in PLM understanding and PLM implementation. The adaptation and customizing of PLM technologies become unavoidable and implicate high expenditure in form of costs, time and effort which is often underestimated by organizations. Despite of the importance of PLM adaptation and PLM customizing and its influence on the success of a PLM implementation project, there is no clear basis for an understanding of what PLM adaptation and customizing really is. Furthermore a lack of solution approaches exists that can guide companies during the process of PLM adaptation and customizing. The aim of this paper is to build a foundation for understanding PLM and the customizing of PLM. Furthermore a solution area beyond the software driven focus will be suggested
\end{abstract}

Keywords: Product lifecycle management, PLM adaptation, PLM customizing, PLM realization, PLM change management, PLM adoption

\section{Introduction}

Product lifecycle management (PLM) has become essential for companies in order to deal with the challenges of the era of digitalization, net economy or in other words the internet of things. For reducing costs, shortening innovation cycle and development schedules [1], acting and collaborating globally by increasing complexity in products and processes, companies require innovative approaches which accompany their products through the entire lifecycle. These approaches built the core idea of PLM. For the purpose of realizing this idea and enabling the management of the company's products all the way across their lifecycle [2], PDM/PLM vendors offer PDM/PLM solutions that represent a combined set of IT application frameworks and a PDM backbone [3].

The implementation of such solutions however requires a cost and time intensive adaptation in special customizing, since the PDM/PLM solution itself as well as the 
enterprise (company), which is implementing the PDM/PLM, has to deal with various challenges, as summarized in figure 1 .

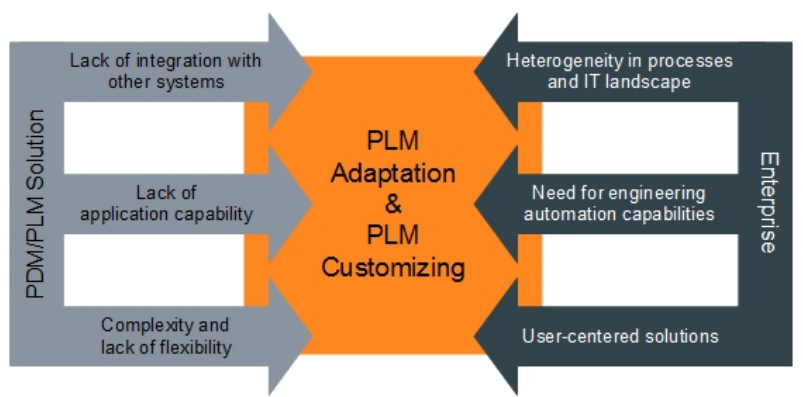

Fig. 1. Challenges and drivers for PLM Adaptation and PLM Customizing

Firstly, companies have diversified processes which are mostly historically grown and a heterogeneous IT landscape that is fragmented through the entire enterprise [4]. Only inside the product development are diverse domains with different requirements. For instance, in the automotive industry the development of electronic components requires other information, data, knowledge and accordingly tools and methods than the development of sheet metal components. In some extent the requirements are extremely domain or task-specific, so an in-house solution is generated or a thirdparty solution is integrated to fulfill these requirements. Unfortunately PDM/PLM vendors can still not offer simple opportunities to integrate third-party task-specific solutions except their own applications [3]. Secondly, PDM/PLM solutions do still not have the capability or functionality to cover the broad base of product development practices that companies execute among different even global product markets [5]. Additionally, companies need intelligent solutions that assist, anticipate and automate engineering activities. However, PDM/PLM solutions as know of today are not capable of generating such intelligence [3]. Thirdly, with the aim of complying with many PLM functionalities, PDM/PLM vendors merged different applications, components or modules in their existing platform and hence increased the technical complexity but on the other hand reduced the flexibility of their products [5]. The companies though need user-centered solutions with a higher level of usability and thus flexibility.

The above specified problems induce a long PLM adaptation process and an expensive PLM customizing procedure. However, also due to the marketing concept of PDM/PLM vendors, companies are not aware of the impact of PLM adaptation and customizing on the success of PLM implementation. Moreover, they are vastly underestimated. Such misalignment can have disastrous results such as a significant extension in project time (double or triple of the originally estimated timeline), vastly increasing costs for PLM implementation as well as unsatisfied, unmotivated PLM project teams and even shut down of the entire PLM implementation.

Due to the importance of PLM adaptation and PLM customizing, this paper primarily aims to give a broad understanding of PLM itself and its adaptation and customizing. 
After clarifying the research approach in chapter 2, a conceptional framework is presented in chapter 3 for better understanding the scope of PLM. In order to describe PLM customizing as a part of PLM adaptation (chapter 4) the terminology of customizing is given in chapter 5. A conceptional framework for PLM customizing is suggested in chapter 6 . Finally in chapter 7 an outlook for further researches and work is discussed.

\section{Research Approach}

The research approach is based on the Design Research Methodology (DRM) [6] and covers a comprehensive research plan, as shown as in figure 2.

The theoretical framework (step 1) and a qualitative study with experts to represent the state of the art in industry (step 2) were given in [7]. Constitutively, this paper focuses on the state of the art in theory (step 3) and suggests a conceptional framework for the PLM and PLM adaptation (step 4). A model for a successful PLM customizing procedure is being developed and validated (step 5) and will subsequently presented in further publications.

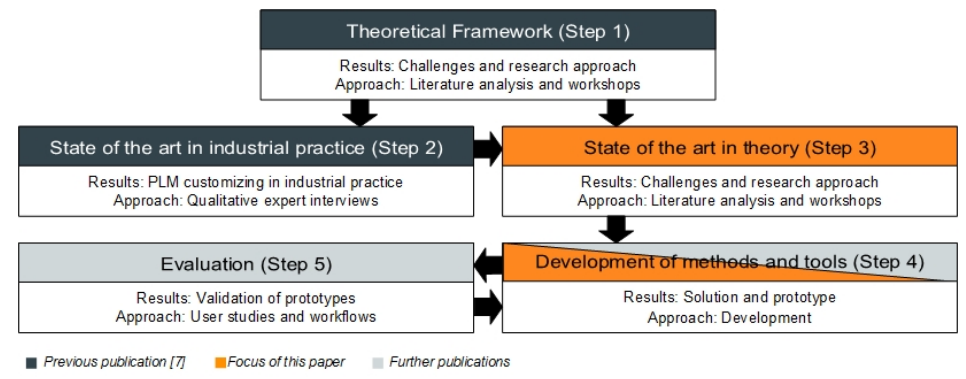

Fig. 2. Research Approach

\section{Conceptional Framework for Understanding PLM}

The basic idea of PLM arose with the evolution of computer-based solutions and applications in engineering design (e.g. computer aided design (CAD)) and manufacturing (e.g. computer integrated manufacturing (CIM)) in the 1970s. In the 1980s the necessity of managing all the engineering data produced by the tools led to the development of engineering data management (EDM) and furthermore product data management (PDM), which represents the backbone for a PLM solution [8]. In the 1990s simultaneously to the advancement of PDM the first generation of enterprise applications was introduced (e.g. enterprise resource planning (ERP), customer relationship management (CRM), supply chain management (SCM)). Each of these applications emphasizes a particular lifecycle phase of a product and does not consider its' whole lifecycle. Consequently, at the end of the 1990s, the PLM approach was born: to enable a platform for creating, organizing and disseminating all product related infor- 
mation, data, knowledge through all stages of a product lifecycle from the ideation to the point of disposal /recycling [2,9].

Since PLM has its roots in computer-based solutions, it is mainly considered as an IT solution and still defined in many industries as a synonym for PDM [10]. However PLM is more than that, it is "an integrated, information-driven approach comprised ... all aspects of a product's life, from its design through manufacture, deployment and maintenance - culminating in the product's removal from service and final disposal" [8].

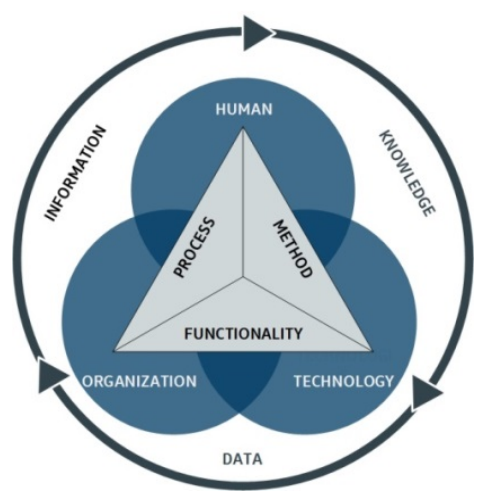

Fig. 3. Conceptional Framework for PLM

In order to realize the main idea of PLM it is essential to understand the scope of PLM in a holistic approach. Hence based on literature, the state of the art and our industrial experience we purposed a conceptual framework for PLM, concerning all relevant aspects of a product lifecycle (figure 3). Mainly the following models provided input for our framework:

- MTO$^{1}$ Approach [11]: The success of implementing computer-aided systems depends on a comprehensive approach taking into consideration the technique, the organization as well as its design but also the employee and his/her qualification. STROHM and ULICH came to this conclusion after many years of analyzing designing computer aided systems (here GRIPS ${ }^{2}$ ) and developed the MTO-Approach. The approach does not only highlight the importance of organization but also comprises the aspects of work psychology in a technical environment. In our framework we expand this approach on further depending aspects in the context of PLM.

- The Engineering Operation System (EOS) [3,12]: In 2013 Fraunhofer IPK and TU Berlin proposed the integrative EOS model with the aim of depicting a holistic approach for product and manufacturing engineering and the associated development environments. The main focus of EOS is the interaction of four different levels or

${ }^{1}$ MTO stands for the german acronyms: $\mathrm{M}$ for „Mensch“ (human), T for Technik (technique), O for „Organisation“ (organization)

${ }^{2}$ GRIPS illustrares the german concept "Gestaltung rechnerunterstützter integrierter Productionssysteme” (eng: desging of computer aided integrated production systems) 
areas: (1) process and organization, (2) engineering activities, (3) data and information and (4) (IT)-tools and applications). Their interaction is key for engineering and this can be used as a foundation to unfold the complete potential of PLM. In addition to product and manufacturing engineering we consider in our framework also the phases of production, after sales management and end of life management, with their related processes and activities.

In the following the components of our framework will be explained.

\subsection{Organization}

Many studies define the organization as an essential component of PLM. Still, a detailed description of the scope of organization in PLM context is not given. In this study organization comprises the structural organization as well as the operation execution. The enterprise size, type and value, the operation level (e.g. global) and the organizational culture all represent important criteria which have to be considered in order to successfully realize PLM. The function of organization covers all management activities (e.g. decision-taking, setting of objectives [2], defining the strategy and vision) and management functions (e.g. governance and compliance, analytics and reporting, economics calculation [13]).

\subsection{Human}

The human factor in PLM context is mentioned in studies concerning the resource aspect, the importance of skills with its relevant facets, as well as in engineering and its activities (e.g. [12]). Beyond these aspects we consider in our concept the approach of information ergonomics and the science of work psychology in PLM context.

\subsection{Technology}

The dimension of information and communication technology (ICT) is very commonly assessed to describe PLM in a most specific way. This aspect is also defined as PLM system to highlight (generally one singular) software system. Furthermore, to describe a whole environment of IT infrastructure which enables PLM, the terminus PLM solution is used. In our study we use the term technology to comprise all "mechanical art" [14] components that purpose the realization of PLM. Additionally to the common PDM/PLM solutions (software \& applications) we also consider technologies such as augmented reality or even enterprise social media ${ }^{3}$.

${ }^{3}$ Enterprise social media is defined as: "Web-based platforms that allow workers to (1) communicate ... or broadcast messages to everyone in the organization; (2) explicitly indicate or implicitly reveal particular coworkers as communication partners; (3) post, edit, and sort text and files linked to themselves or others; and (4) view the messages, connections, text, and files communicated, posted, edited and sorted by anyone else in the organization at any time of their choosing.”[15] 


\subsection{Process}

The processes are usually considered as a part of the organization within the scope of business process in many studies analyzing PLM components. Supplementary regarding the lifecycle processes of a product a process oriented focus on PLM also exists. In our study, additionally to existing approach, we consider process as an organizational specification and moreover as framework which is agile and flexible since it is "lived" and formed by people in order to fulfill activities in the lifecycle of the product. Therefore, processes are represented in our framework in combination with organization and the human factor.

\subsection{Method}

A method is defined as „a particular procedure for accomplishing or approaching something" [16]. In the context of PLM such procedure is usually mentioned as a component for company-specific PLM solutions and used as a synonym for tools, techniques or equipment which support the management of information through the product lifecycle. Similarly we characterize methods as procedure for performing the activities or tasks by people in a technological environment. Thus, methods are illustrated with the focus of human factor and the technology.

\subsection{Functionality}

In the scope of PLM functionalities are mentioned in order to define capabilities of PDM/PLM solutions. Beyond that we consider the functionality as a technological framework which supports the mapping of processes defined by the organization. Therefore we represent the functionality of PLM in the context with organization and technology.

\subsection{Information / Knowledge / Data}

The main idea of PLM involves all facets of knowledge management, since PLM supports the gaining, organization and reusing of knowledge through the lifecycle of a product [9]. Beyond the approach of information management in the scope of PLM, which is also presented as closed-loop PLM (e.g. [17]), in our concept, we also consider the vision of knowledge. While information is defined as data "that is organized to describe a particular situation or condition', knowledge additionally includes perspectives, concepts, truths, beliefs, judgments, expectations, and know-how in the scope of human factor [18].

\section{$4 \quad$ PLM Adaptation and PLM Customizing}

The realization of PLM in companies implies an alteration in the whole enterprise, since PLM concerns the entire company environment. Based on our conceptional 
framework we illustrate the three types of PLM adaptation as PLM change management, PLM adoption and PLM customizing (figure 4).

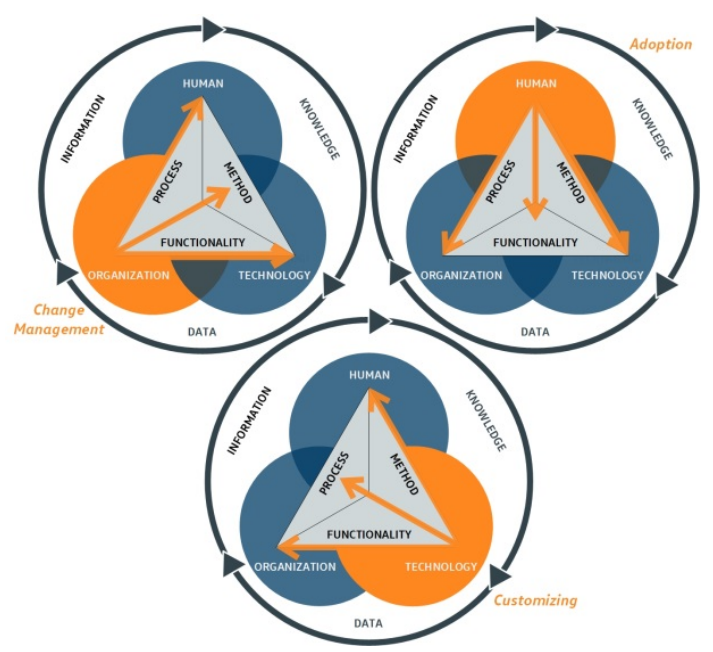

Fig. 4. Scope of PLM Adaptation

We describe the organizational adaptation as PLM change management. The main focus of the adaptation in the context of PLM change management is the organizational environment but it affects all PLM components such as human and technology through the adaptation of processes, methods and functionalities. PLM change management contains the approaches of cultural change management, business reengineering and others. On the other hand PLM adoption is described as the human specific adaptation of PLM and includes aspects such as software ergonomics or humancomputer interaction. Although the human factor is at the center, the implication of PLM adoption broadens all aspects of PLM with the adaptation of methods, processes and functionalities. In this paper, we concentrate on PLM customizing, which can be described as the technological adaptation of PLM with an impact of the entire PLM scope including the human factor and the technology as well as the processes, the functionalities and the methods.

\section{$5 \quad$ Understanding Customizing}

In industry PLM customizing is interpreted very differently (e.g. [7]) even within the same PLM project. Hence a homogeneous understanding of customizing is essential for a successful realization of PLM.

Customizing or customization is defined in literature as "the action of modifying something to suit a particular individual or task" [16]. In the context of business and management customizing is the "design and development of a product to meet the specific requirements of a single customer" [19]. Besides the view of business management, economics or academic, in detail the definition of customizing strongly 
differs from the product itself which is customized and from the producer of the product. In the field of information and communication technology especially enterprise software terms such as configuration, modification, parametrization, in house development or out of the box (OOTB) are used to describe customization. The business area of SAP describes customizing as a tool-assisted parametrization and adaptation of the software to the company-specific requirements without any programming [20], whereas the PLM vendor Siemens PLM characterizes customizing as any adaption, extension and change in the software by using several different applications and toolkits including code generation and programming [21].We define customizing, as shown in Figure 5, as any change and individualization in the context of PDM/PLM solution or rather PLM technology. For instance, in the scope of a PDM/PLM solution PLM customizing comprises workflow generation, a new object in data modelling or an added attribute as well as an extension programming for task-specific functionalities.

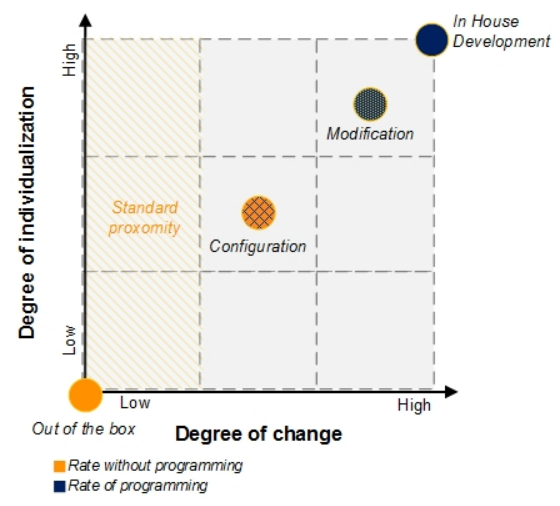

Fig. 5. The Scope of Customizing

The raise in change of the PLM technology leads to more expenditure in programming, but usually also to more functionality. Additionally the release ability is getting reduced. On the other hand more individualization induces larger process mapping but also less flexibility. Supplementary the dependencies and mutual reactions of the PLM technology increase. Therefore it is very important to understand PLM customizing towards defining a strategy for PLM adaptation.

\section{Solution space for PLM Customizing}

As mentioned in chapter 1, for the purpose of enabling a better fit of the PLM technology with the company-specific requirements PLM customizing is inevitable. After defining the comprehension of PLM customizing we suggest a solution space for PLM customizing as shown in Figure 6 aiming to support the decision of how to customize in the scope of PLM technology. In our concept companies which implement 
the PLM technology, are defined as PLM user whereas the provider of the PLM technology is defined as PLM vendor.

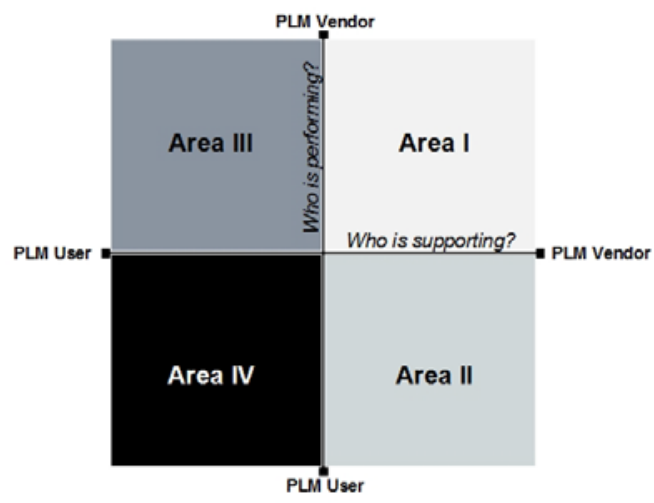

Fig. 6. Solution Area for PLM Customizing

The goal of both PLM user and PLM vendor should be Area I. In this space, any changes in the PLM technology are conducted by the vendor and hence included in the standard technology; the support is also done by the vendor. The collaboration between vendor and user both on the strategic and on the operative level is very high. This leads to a "win-win situation", especially for innovative business segments. For instance many industry specific modules offered by PDM/PLM vendors are based on special requirements from PDM/PLM users or even more from their "in-house solutions” which are then converted in the out of box solution. Area II comprises all kinds of configuration and is usually performed by using the applications or toolkits suggested and supported by the vendor. Although this area is also considered as "good customizing" it is associated with many costs concerning performing and testing (including regression tests). Beyond that the toolkits and applications which are offered by the vendor to perform the configuration can change or even become obsolete. In this case the maintenance of the scope of customizing has then to be supported by the PLM user and hence will move in Area IV. Area III comprises commonly the integration and interoperability subjects, with other words the PLM extensibility. The initial customizing is performed by the vendor and the support and operation is done by the user. The integration of PDM/PLM solutions with CAD solutions or ERP solutions are typical examples of this area. It is also possible that the vendor develops certain interfaces for the user, which will then be placed in Area I. In that case it is very important to have verified regulations and agreements regarding the collaboration and cooperation between vendor and user. Area IV comprises all kind of modification and extension programming and should be avoided by the user. Not only that the performing, testing and supporting of customizing causes very high costs and extensions of the implementation time but also the ability to release a new PLM technology is vulnerable. However, in practice, many companies are located in Area IV and imperatively need to develop strategies to change in a different area. 


\section{$7 \quad$ Conclusion and Outlook}

The realization of PLM poses many challenges for companies that are implementing PLM technologies as well as for the vendor of the PLM technology itself. Especially customizing, as a part of PLM adaptation, has a broad and varied impact of PLM implementation. In this paper, we primarily provided a comprehensive framework for understanding the main idea of PLM. Adapted from the proposed PLM framework we described PLM customizing as a part of PLM adaptation and suggested a solution area for companies to deal with the challenges concerning PLM customizing.

Since PLM customizing in the state of the art is unavoidable, studies that suggest a detailed framework for executing PLM customizing would be very valuable. Such studies should give a deep understanding of the PLM customizing process by considering not only the input and output parameters, but also the drivers and the stakeholders. For instance a stakeholder analysis under consideration the customer-supplier relationship would help organizations to define the suitable collaboration model and method within the PLM implementation project, not only on the operative and tactical level, but also on the strategic level. Furthermore, there is a lack of usable, expedient KPIs for PLM customizing. Studies that define such parameters and propose a suitable valuation model would draw great attention not only in the industrial, but also in the academic field.

\section{Acknowledge}

The results, opinions and conclusions expressed in this thesis are not necessarily those of Volkswagen Aktiengesellschaft.

\section{References}

[1] Jackson C. The CIO's Role in PLM: Facilitation "Great Product" Development to Drive Economic Recovery.

[2] Stark J (2018) Product Lifecycle Management (Volume 3): The Executive Summary. Springer, Cham.

[3] Damerau T, Hayka H, Neumeyer S, Woll R, Stark R (2014) Intelligent Information Technologies to Enable Next Generation PLM. in Fukuda S, Bernard A, Gurumootrthy B, Bouras A, (Eds.). Product Lifecycle Management for a Global Market: Revised Selected Papers. Springer. Heidelberg, Berlin, pp. 485-495.

[4] Holler M, Dremel C, Herterich M, Uebernickel F, Brenner W (2017) Product Lifecycle Management im Konzernumfeld: Herausforderungen, Lösungsansätze und Handlungsempfehlungen. HMD - Praxis der Wirtschaftsinformatik:1-18.

[5] Hewett A (2010) Product Lifecycle Management (PLM): Critical Issues and Challenges in Implementation. in Nambisan S, (Ed.). Information technology and product development. Springer. New York [u.a], pp. 81-105. 
[6] Blessing LTM, Chakrabarti A (2009) DRM, a design research methodology. Springer, Dordrecht, New York.

[7] Sucuoglu E, Exner K, Stark R (2017) PLM Customizing: Results of a Qualitative Study with Industrial Experts. in Ríos J, Bernard A, Bouras A, Foufou S, (Eds.). Product Lifecycle Management and the Industry of the Future. Springer International Publishing. Cham, pp. 49-58.

[8] Grieves M (2006) Product lifecycle management: Driving the next generation of lean thinking. McGraw-Hill, New York.

[9] Ameri F, Dutta D (2005) Product Lifecycle Management: Closing the Knowledge Loops. Computer-Aided Design and Applications 2(5):557-90.

[10]Abramovici M (2010) PLM -Best Practice Einführungsstrategien, Rapperswil.

[11]Strohm O, Ulich E, (Eds.) (1997) Unternehmen arbeitspsychologisch bewerten: Ein Mehr-Ebenen-Ansatz unter besonderer Berücksichtigung von Mensch, Technik und Organisation. vdf Hochschulverlag, Zürich.

[12]Lünnemann P, Wang WM, Stark R, Manteca PI (2017) Engineering Activities: Considering Value Creation from a holistic Perspective. in Jardim-Gonçalves R, Mendonça JP, Pallot M, Zarli A, Martins J, Marques M, (Eds.). Engineering, Technology \& Innovation Management Beyond 2020: New Challenges, New Approaches. IEEE. Danvers, pp. 315-323.

[13]Eigner M, Stelzer R (2009) Product Lifecycle Management: Ein Leitfaden für Product Development und Life Cycle Management. 2nd ed. Springer, Dordrecht [u.a.].

[14]Arthur WB (2009) The Nature of Technology: What It Is and How It Evolves. Free Press, New York.

[15]Leonardi PM, Husman M, Steinfield C (2013) Enterprise Social Media: Definition, History, and Prospects for the Study of Social Technologies in Organizations. Journal of Computer-Mediated Communication 19:1-9.

[16]Oxford Dictionary. Englisch Oxford Living Dictionaries. https://en.oxforddictionaries.com/.

[17]Kiritsis D (2011) Closed-loop PLM for intelligent products in the era of the Internet of things. Computer-Aided Design(43):479-501.

[18]Baskerville R, Dulipovici Alina (2015) The Theoretical Foundations of Knowledge Management. in Edwards JS, (Ed.). The Essentials of Knowledge Management. Palgrave Macmillan. Hampshire, pp. 47-91.

[19]Law J, (Ed.) (2016) A Dictionary of Business and Management. 6th ed. Oxford University Press, Oxford.

[20]Thomas O, Scheer A-W (2003) Referenzmodell-basiertes (Reverse-) Customizing von Dienstleistungsinformationssystemen: Heft 173. ISSN: 1438 5678, Institutsveröffentlichung, Saarbrücken, Deutschen Forschungszentrum für Künstliche Intelligenz, Institut für Wirtschaftsinformatik.

[21]S-PLM (2008) Getting started with Customization. in Siemens Product Lifecycle Management Software Inc., (Ed.). Teamcenter 8.3 HTML Help Collection. 